ger als 6 sich barythaltig erwiesen. Die procentische Zusammensetzung derselben ergab sich nemlich wie folgt:
I.
II.
III.
IV.
v.
VI.

$\begin{array}{lllllll}\text { Kieselsäure } & 72,006 & 65,750 & 65,874 & 63,825 & 64,031 & 69,531\end{array}$

$\begin{array}{lllllll}\text { Thonerde } & 10,849 & 18,220 & 19,183 & 19,125 & 19,323 & 11,416\end{array}$

$\begin{array}{lllllll}\text { Fisenoxyd } & - & - & - & - & - & 3,070 \\ \text { Eisenoxydul } & - & 0,300 & 0,134 & 0,262 & 0,092 & -\end{array}$

$\begin{array}{lllllll}\text { Kalk } & \mathbf{1 , 9 3 2} & 0,837 & \mathbf{0 , 6 0 0} & 0,974 & 0,437 & \mathbf{2 , 7 3 4}\end{array}$

$\begin{array}{lllllll}\text { Baryt } & 2,518 & 0,500 & 0,424 & 0,322 & \text { Spur } & \text { Spur }\end{array}$

$\begin{array}{lrrrrrr}\text { Natron } & \mathbf{1 , 7 5 8} & \mathbf{3 , 7 7 4} & \mathbf{2 , 8 3 6} & \mathbf{1 , 7 7 5} & \mathbf{2 , 3 5 0} & \mathbf{1 , 1 4 2}\end{array}$

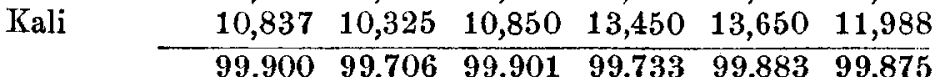

Von den übrigen Mineralien, welche keine reinen Species, sondern Gemenge von Silikaten, Kiesen etc. waren, enthielten nur drei Baryt und diese auch nur in Spuren.

\title{
Ueber eine neue Verunreinigung des Baryumchlorids.
}

$$
\text { Von Demselben. *) }
$$

Unter den in meinem Laboratorium vorräthig gehaltenen Analysir-Proben befindet sich seit vielen Jahren ein (oft ernouertes) Gemenge ron

Quecksilberchlorid, salpeters. Baryt,

Strontium-, Calcium - und Ammoniumchlorid.

Vor mehren - wenigstens fünf - Jahren wurde mir zum ersten Male auf die Frage, welche Säuren in dieser Probe seien, auch Schwefelsäure genannt. Ich musste eine solche Angabe natürlich als eine irrige abweisen, die Quelle auf nicht sorgfältig gereinigtes Reagensglas — wie das ja oft vorkommt - zurückführend.

Als sich jene Angabe wiederholte, liess ich mir die durch Baryumchlorid erhaltene Reaction zeigen; sie bestand in einer sehr schwachen Trübung, fast Opalisirung, welche zwar nicht das Ansehen einer durch schwefelsauren Baryt entstandenen Trübung, sondern ein mehr flockiges besass, indessen vorläufig als eine Schwefelsäure-Reaction betrachtet werden musste, da sie durch Säuren nicht wieder verschwand.
*) Als Separatabdruck aus dessen Vierteljahrsschrift vom Hrn. Verf. erhalten.
II. $L$. 
Ich löste nun in einem mit destillirtem Wasser ausgespühlten Glase von obigem Gemenge selbst etwas auf und fügte von der vorräthigen Baryumchloridlösung hinzu. Im ersten Momente blieb alles klar, aber nach kaum zwei Sekunden stellte sich eine schwache Opalisirung ein, die allmählig etwas stärker wurde, und es kam binnen einer halben Stunde sogar zur Ausscheidung einiger dichten weissen, durch Salzsäure anscheinend nur wenig sich verändernden Flocken. Vorläufig war nun meine Weisheit zu Ende und ich nahm mir vor, der Sache gelegentlich ernst nachzuforschen, schob sie jedoch von einem Semester zum andern auf und hätte sie vielleicht ganz liegen lassen, wenn ich nicht neuerdings wiederholt darüber interpellirt worden wäre.

Anfangs wusste ich nicht, wie die Sache anzugreifen sei, prüfte auf's Gerathewohl ein Salz des Gemenges nach dem andern mit Baryum - Chlorid, und fand dabei, dass die Ursache der Trübung nur im Quecksilberchlorid liege. Sollte dieses Schwefelsäure enthalten? Dann hätte es aber mit dem Baryt- und Strontiansalze des Gemenges keine klare Lösung geben können!

Da nun das Quecksilberchlorid durch Baryumchlorid sich trübte, nicht aber durch (den in dem Gemenge befindlichen) salpetersauren Baryt, und letzteres Faktum sich bei Wiederholung bestätigte, so musste in dem Baryumchlorid, resp. in einer Verunreinigung desselben, der Friedensstörer gesucht werden.

Auf die Bereitung des Baryumchlorids zurückgehend, wurde es mir bald klar, dass, wenn das Schwefelbaryum nicht vollständig durch Salzsäure zerstört wird, der ỉbrig gebliebene Rest von Schwefelbaryum nach und nach in unterschwefeligsauren Baryt übergeht, und dieser möglicherweise spurweise dem Baryumchloride anhaften bleibt, soferne nicht umkrystallisirt wird. Enthielt daher mein $\mathrm{Ba}$ ryumchlorid unterschwefligsauren Baryt, so musste es durch Einwirkung eines oxydirenden Agens von selbst trübe werden, und in der That ward es das auch, als ich seine Lösung mit Salpetersäure versetzt und einigemal aufgekocht hatte.

Es stand mithin fest, dass mein Baryumchlorid, seit Jahren aus ein und derselben Quelle bezogen, unterschwefeligsauren Baryt enthielt, jedoch nur in Spuren, denn Quecksilberchlorid wird schon von einer sehr verdünnten Lösung des unterschwefeligsauren Natrons stark weiss gefällt. Ein Ueberschuss ron unterschwefeligsaurem Natron macht 
den Niederschlag erst gelb und bringt ihn dann bis auf eine geringe schwarze Ausscheidung von Schwefelquecksilber wieder zum Verschwinden.

Von einer Verunreinigung des Baryumchlorids mit unterschwefligsaurem Baryt scheint man bisher keine Ahnung gehabt zu haben, wenigstens finde ich nirgends eine Andeutung darüber.

$H: L$.

\section{Ein neues Diatomeen-Lager in Schlesien nach Dr. B le isch in Strehlen und Prof. Cohn in Breslau.}

In Schlesien sind bis jetzt nur zwei derartige Lager, bei Gronowitz in Oberschlesien und bei Tillowitz, entdeckt worden. Die hier in Rede stehende, neue, sehr reichhaltige Ablagerung wurde bei Ruppertsdorf (Peetsch) $1 / 4$. Meile von Strehlen bei Gelegenheit eines Bohrversuches aut' Braunkohlen aufgefunden. Dieselbe ist diluvialen Ursprungs, in ebener Gegend 18 Fuss tief, enthält nach der mikroskopischen Analyse von $\mathrm{Bleis}$ ch 17 verschiedene Formen und besteht nach Prof. Kroker in $100 \mathrm{Thl}$. (lufttrocken) aus:

Feuchtigkeit

Organischen Stoffen

Thonerde, Eisen - und etwas Manganoxyd

Kalk

Schwefelsäure

Phosphorsäure

Kohlensäure

Kieselerde in Alkalien löslich, geringen Mengen Magnesia und Alkalien

Unlöslichem in Säuren (Thon und Sand)

$$
\begin{array}{r}
9,43 \% . \\
11,52 " \\
3,70 " \\
38,07 " \\
0,24 " \\
0,14 " \\
22,80 "
\end{array}
$$

$$
\begin{gathered}
12,36, " \\
1,47, " \\
\hline 100,00 .
\end{gathered}
$$

Unter den fremdartigen Bestandtheilen dieses DiatomeenLagers fand Cohn ausser dem reichlichen Pollen von Pinus und Laubhölzern eine ungeheure Anzahl ron schwar\% en mikroskopischen Krystallen und Splittern, deren chemischer Charakter bei ihrer Unlöslichkeit in Süuren, noch nicht bestimmt werden konnte und welche sich nicht bloss $\mathrm{z}$ wischen den Diatomeenschalen, sondern auch im Innern derselben befinden. Cohn schliesst hieraus, dass die Krystalle nicht ursprünglich in dem zum Mergel erhörteten 